ERJ

Engineering Research Journal

Faculty of Engineering

Minouflya University

\title{
INTERLAMINAR SHEAR BEHAVIOR OF CROSS-PLY GFRP COMPOSITE WITH DIFFERENT OFF-AXIS ANGLES
}

\author{
A.I. Selmy, U.A. Khashaba, I.A. El-Sonbaty, M.A. Abd El-Baky \\ Mechanical Design and Production Engineering Department, Faculty of Engineering, \\ Zagazig University, P.O. Box 44519, Zagazig, Egypt.
}

\begin{abstract}
Double-notch and short-beam shear test supports have been designed and manufactured to measure the interlaminar shear strength of cross-ply composite laminate with different off-axis angles. A cross-ply $\left[0^{\circ} / 90^{\circ}\right]_{2 s}$ glass/polyester laminate was manufactured using hand lay-up technique. The laminate was cut at different off-axis angles $\left(0^{\circ}, 15^{\circ}, 30^{\circ}\right.$ and $\left.45^{\circ}\right)$ to give $\left(\left[0^{\circ} / 90^{\circ}\right]_{2 s},\left[15^{\circ} /-75^{\circ}\right]_{2.5},\left[30^{\circ} /-60^{\circ}\right]_{2 s,},\left[45^{\circ} /-45^{\circ}\right]_{2 s}\right)$ stacking sequences. In double-notch shear (DNS) test, the effect of shear length on interlaminar shear strength was investigated. In shortbeam shear (SBS) test, the effect of specimen width on apparent interlaminar shear strength was studied. The interlaminar shear stress distribution for both DNS and SBS specimens were obtained. Failure modes of DNS and SBS specimens were investigated.

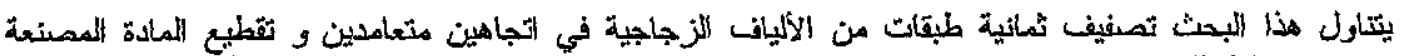

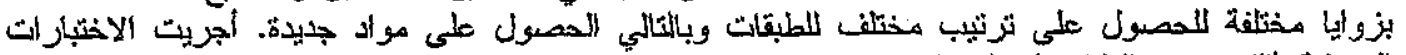

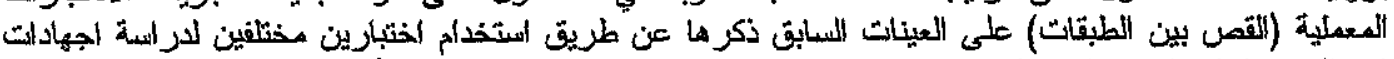


الاختبالرين.
\end{abstract}

Keywords: Composite, short-beam, double-notch, cross-ply, off-axis angle, interlaminar shear.

\section{INTRODUCTION}

The interlaminar shear strength may be defined as the resistance of a layered composite to internal forces that tend to reduce relative motion parallel to, and between the layers [1].

The interlaminar shear strength is a critical parameter in most fibrous composites because its relatively low value compared with the longitudinal tensile strength $[2,3,4]$. The interlaminar shear strength, the topic of this study, could be measured by several methods, including double-notch (DNS) [5,6], short-beam (SBS) $[1,6,7]$, and losipescu tests [8].

Although many shear test methods have been developed for use with composite materials over the years, the results obtained from these tests often have been inconsistent. Each method has its limitation and inherent inaccuracies [9]. In this work two test methods will be described and discussed.

DNS method defined by ASTM D3846-02 [10] is an attractive method for measuring interlaminar shear strength of reinforced thermosetting plastics in flat sheet form in thicknesses ranging from 2.54 to 6.60 $\mathrm{mm}$. This test is inexpensive, simple and can be used at cryogenic temperatures. The dimensions of DNS specimens, and the test technique have a great influence on the bending of the specimen and the stress concentration over the length between the two notches.
SBS test (ASTM D2344-84 [11]) has become a widely used method for characterizing the interlaminar failure resistance of fiber-reinforced composites. Its main advantage is simplicity. This method suffers from the disadvantages of nonuniform stresses, states of combined stress, and sever stress concentrations [6]. As pointed out in the title of ASTM Standard D 2344, this method measures the "apparent" interlaminar shear strength of composite materials [1].

Shindo et al. [7] determined the interlaminar shear strength of G-10CR glass-cloth/epoxy laminates using both SBS and DNS tests, results showed that the average interlaminar shear stress of short-beam specimens was less than the average interlaminar shear stress of double-notch specimens.

The objective of the present paper is to determine interlaminar shear strength of cross-ply GFR/polyester composite with different off-axis angles. The double-notch and short-beam shear tests have been conducted on GFRP laminate manufactured by hand lay-up technique. In DNS test, the effect of shear length on interlaminar shear strength has been studied. While, in SBS test, the effect of specimen width on the interlaminar shear strength has been studied. 


\section{EXPERIMENTAL WORK}

\subsection{Material and Specimen Preparation}

A cross-ply, $\left[0^{\circ} / 90^{\circ}\right]_{2 s}$, GFR/polyester laminate was manufactured using hand lay-up technique. The constituent materials and their elastic properties are illustrated in Table 1 and 2.

Table 1. The constituent materials of GFRP composite laminates

\begin{tabular}{|c|c|}
\hline Materials & Type \\
\hline $\begin{array}{l}\text { Matrix } \\
\text { Catalyst }\end{array}$ & $\begin{array}{l}\text { Polyester resin (SIROPOL } 8230) \\
\text { Cobalt naphthanace }(0.5 \% \text { of matrix } \\
\text { volume) }\end{array}$ \\
\hline & $\begin{array}{l}\text { Methyl Ethyl Ketone Peroxide ( } 0.6 \% \text { of } \\
\text { matrix volume) }\end{array}$ \\
\hline Reinforcement & E-glass (Roving) $\rho_{L}=2200 \mathrm{~g} / \mathrm{km}$ \\
\hline
\end{tabular}

Table 2. The properties of $\mathrm{E}$-glass fiber and polyester resin

\begin{tabular}{|l|cc|}
\hline \multicolumn{1}{|c|}{ Properties } & E-glass & Polyester resin \\
\hline Density $\left(\mathrm{Kg} / \mathrm{m}^{3}\right)$ & 2560 & $1100-1500$ \\
Tensile strength $(\mathrm{MPa})$ & 2000 & $40-90$ \\
Tensile modulus $(\mathrm{GPa})$ & 76 & $1.2-4.5$ \\
Poisson's ratio & 0.25 & $0.37-0.39$ \\
\hline
\end{tabular}

Eight templates were used to lay the fiber bundles in $0^{\circ}$ and $90^{\circ}$ directions. The parallel bundles of fibers were fixed on the frame of the templates using small pins. The normal distance between each adjacent parallel bundles was $5 \mathrm{~mm}$. The upper and lower surfaces of the mould were glass plates treated by wax. The first layer is the polyester resin on the lower glass plate. The first template with $0^{\circ}$ oriented fibers was placed on the resin. Rolling the fibers impregnates them, squeezes any excess resin, displaces the air outwards. When the ply was fully impregnated, the bundles were loosen from the template. An amount of polyester resin followed by a template with $90^{\circ}$ oriented fibers was placed and so on until the whole laminate is constructed. The last layer was resin covered by a sheet of aluminum foil which was rolled by a smooth round aluminum pipe to remove any excess resin from the laminate surface and keep its thickness constant for the whole laminate. The second glass plate was placed upon the laminate and a $25 \mathrm{~kg}$ weight was distributed over the glass plate. After $24 \mathrm{~h}$ the glass plates and aluminum foil were removed and the laminate was completely cured at room temperature for 21 days giving a laminate with thickness varying from 6.3-6.4 mm. The plate was taken to the workshop and specimens were cut to the required dimensions using sawing and milling machines. The fiber volume fraction was determined experimentally using the ignition test according to BS 3691 [12]. The average value of fiber volume fraction was $42.59 \%$.

All tests were carried out on a universal testing machine (testometric $200 \mathrm{kN}$ ). Cross-head speed of its loading member was $2 \mathrm{~mm} / \mathrm{min}$.The load- deflection curves were obtained from the computer unit of the testing machine.

\subsection{Double-Notch Shear (DNS) Test}

Double notch shear tests were conducted to examine the effect of shear length on interlaminar shear stress of cross-ply GFR/polyester laminates with different off-axis angles. The cross-ply [0/90]2s laminate was cut at different off-axis angles $\left(0^{\circ}, 15^{\circ}, 30^{\circ}, 45^{\circ}\right)$ to give $\left([0 / 90]_{2 s},[15 /-75]_{2 s},[30 /-60]_{2 s},[45 /-45]_{2 s}\right)$ stacking sequences.

The interlaminar shear strength, as determined by this test method, are measured by applying a compressive load to notch specimens of uniform width. The specimens are loaded in a supporting fixture to prevent the specimen buckling, Fig. 1.

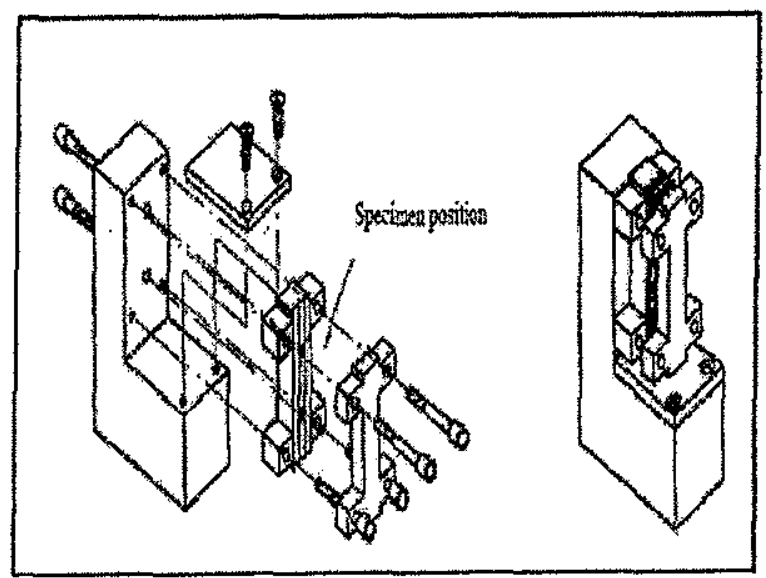

Fig. 1 Schematic of anti-buckling fixture [13].

\subsubsection{Preparation of (DNS) specimens}

The test specimens were cut into strips with $79.5 \times 13 \mathrm{~mm} 2$ using a rotating saw with narrow pitch to prevent the damage during cutting process. The width of the specimen was further machined up to $12.7 \pm 0.05 \mathrm{~mm}$ using a milling machine. two centrally located notches machined halfway through the specimen width and spaced a $(\mathrm{SL}=4,7,10 \mathrm{~mm})$ distance apart on opposing faces, Fig. 2. The quality of notch cutting has a significant effect on the test results. Undercutting (where the notch doesn't reach. the midplane of the specimen) leads to an increase in the measured strength. Over cutting (beyond the midplane of the specimen) leads to a decrease in the measured strength [6]. Three specimens for each shear length were tested.

\subsubsection{Testing}

Each notched specimen was held in the anti-buckling fixture. The specimen is supported along its entire length, with the assembling screws secured fingertight, $0.1 \mathrm{Nm}$, to allow free movement along the vertical axis. The specimen is then end-loaded in 
compression whilst held in the fixture. The interlaminar shear stress (ILSS) was calculated by the following equation:

$\mathrm{ILSS}=\frac{F_{\max }}{w \times S L}$

where: $F_{\max }$ is the maximum load. $w$ is the width of specimen. $S L$ is the shear length.

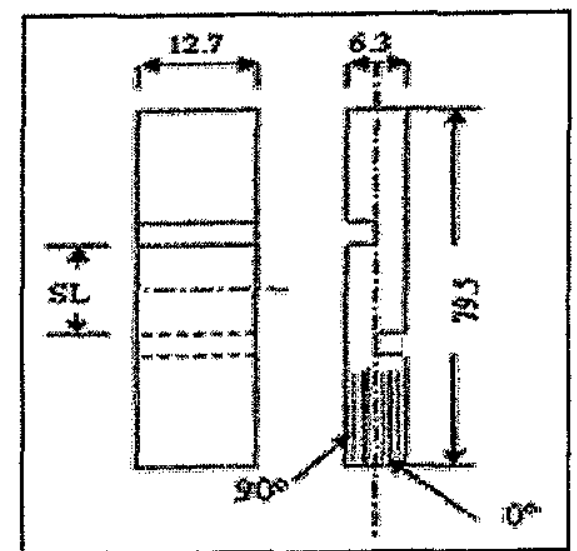

Fig. 2 Double-notch shear specimen DIMS in mm.

\subsection{Short Beam Shear (SBS) Test}

\subsubsection{Preparation of (SBS) specimens}

The test specimens were cut into strips with $38 \mathrm{~mm}$ total length using a rotating saw. The effect of specimen width on the apparent interlaminar shear strength was studied. The widths of the tested specimens were machined up to $(7.5,12.7$, and 25 $\mathrm{mm})$ using a milling machine.

\subsubsection{Testing}

Each specimen was placed on two roller supports that allow lateral motion. The distance between two roller supports (span length) was $31.5 \mathrm{~mm}$. The load was applied directly at the center of the specimen. The beam was loaded until fracture occurred. The fracture load was taken as a measure of the apparent shear strength of the material. Deflection was measured by the measurement of the motion of the loading nose. The failure load was interpreted as the first maximum load attained. Details about the nose and support diameters are illustrated in Fig.3(a). Short-beam shear specimen dimensions are illustrated in Fig.3 (b).

\subsubsection{Shear stress}

The maximum stress (ILSS) was calculated by the following equation:

ILSS $=0.75 \times \frac{F_{u}}{w \times t}$

where: $w, t$ are the width, thickness of specimen.

$F_{u}$ is the applied load at the failure point.


(b)

Fig. 3 (a) Short beam shear test support.

(b) Specimen dimensions in $\mathrm{mm}$.

\section{RESULTS AND DISCUSSION}

\subsection{Interlaminar Shear Properties of GFRP Specimens}

Interlaminar shear properties of cross-ply GFRP composites with various off-axis angles were determined experimentally using double-notch shear and short-beam shear tests.

\subsubsection{Double-notch shear results}

\section{- Interlaminar shear strength}

The effect of off-axis angles $\left(\theta^{\circ}=0^{\circ}, 15^{\circ}, 30^{\circ}\right.$, and $\left.45^{\circ}\right)$, and shear length $(4,7$, and $10 \mathrm{~mm})$ on the shear strength of GFRP specimens have been investigated. Figs. 4 to 7 show the load-displacement diagrams of the testing machine in double-notch shear test for cross-ply laminate with different off-axis angles. The main characteristic of these curves is the linear behavior up to the maximum point followed by a catastrophic failure.



Fig. 4 Load-displacement diagram of cross-ply laminate with various shear lengths. 


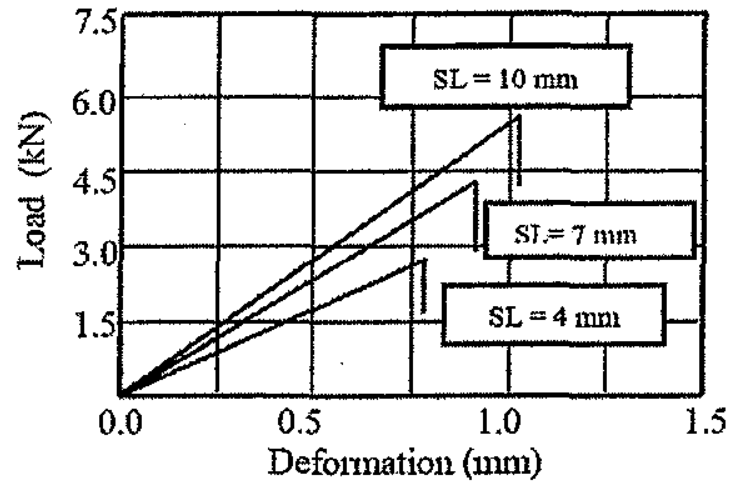

Fig, 5 Load-displacement diagram of $\left[15^{\circ} /-75^{\circ}\right]_{2 s}$ laminate with various shear lengths.



Fig. 6 Load-displacement diagram of $\left[30^{\circ} /-60^{\circ}\right] 2 \mathrm{~s}$ laminate with various shear lengths.

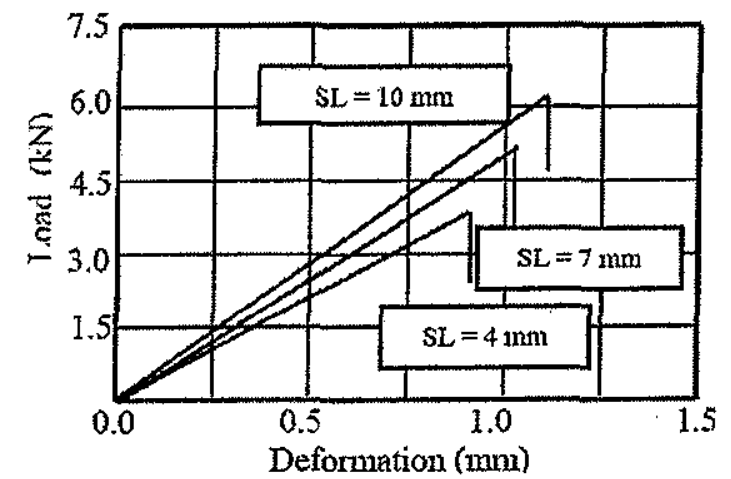

Fig. 7 Load-displacement diagram of $\left[45^{\circ} /-45^{\circ}\right] 2 \mathrm{~s}$ laminate with various shear lengths.

Figs. 8 shows the relationship between the average values of interlaminar shear strength at failure and the shear length.

The results in Fig. 8 indicate that, as shear length increases the value of interlaminar shear stress decreases. The maximum interlaminar shear strength was obtained by extrapolating the curve $\tau L=f(S L)$ to $\mathrm{SL}=0$ [6]. As shear length increases the applied load increases so the bending stress increases. To minimize bending stress on the test specimen shear length must be so small (shear length $=0$ ) so the value of the maximum interlaminar shear strength was obtained.

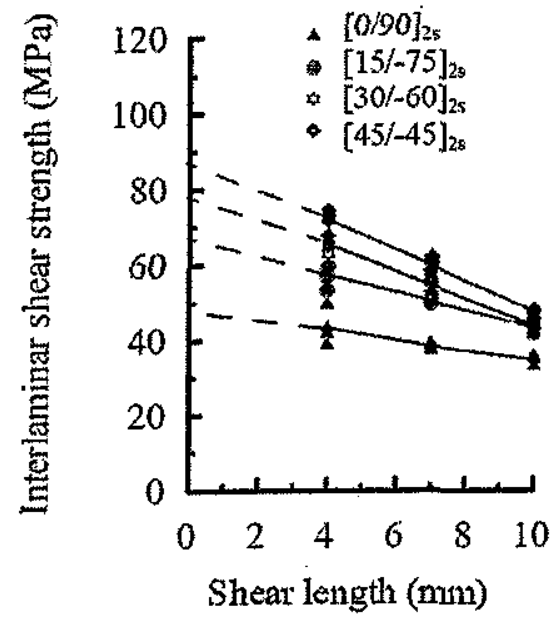

Fig. 8 Relationship between the interlaminar shear strength and shear length of cross-ply GFR/polyester laminate with different off-axis angles.

\section{- Failure modes}

In cross-ply laminate with different off-axis angles, failure of the specimen started by visible cracks across the width of the specimen (across the shear plane between the two centrally located notches) perpendicular to the loading direction followed by visible and complete separation between the two central layers, Fig. 9.



Fig. 9 A double-notch failed specimen.

\subsubsection{Short-beam shear results}

\section{- Interlaminar shear strength}

The interlaminar shear behavior of GFRP composite specimens was studied using SBS test. The effect of off-axis angle $\left(\theta^{\circ}=0^{\circ}, 15^{\circ}, 30^{\circ}\right.$, and $\left.45^{\circ}\right)$, and specimen width $(7.5,12.7$, and $25 \mathrm{~mm})$ on the shear strength of GFRP specimens have been investigated. Figs. 10 to 12 show the load-deflection curves of cross-ply specimens with different $\theta^{\circ}$ in SBS test. The main characteristic of these curves is the linearity up to the maximum point followed by catastrophic fracture. In the later loading stage, a slight degree of nonlinearity exists.

Fig. 13 shows the dependence of intexlaminar shear stress in SBS test on the specimen width. The results show that as the specimen width increases the interlaminar shear strength decreases. Similar results were observed by [1]. When the same force is applied to the specimens with various widths, the specimens with smaller widths are subjected to lower shear stresses, and thus should exhibit higher strengths [1]. 


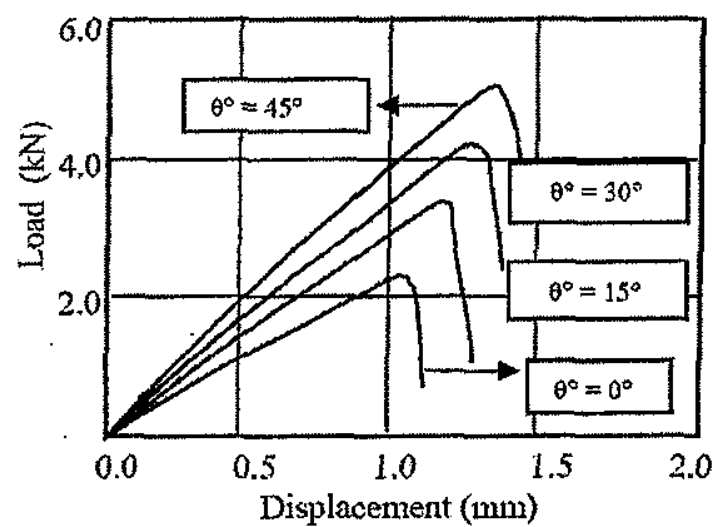

Fig. 10 Load-displacement diagram of cross-ply short beam shear specimens with different off axis angles (width $=7.5 \mathrm{~mm}$ ).

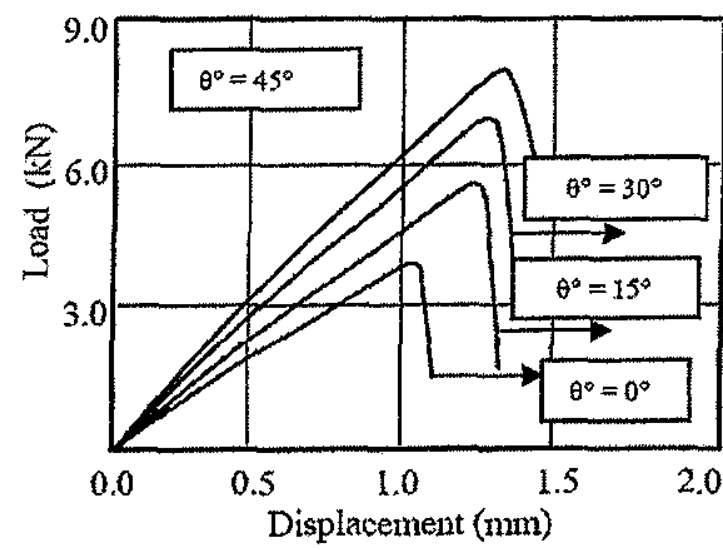

Fig. 11 Load-displacement diagram of cross-ply short beam shear specimens with different off axis angles (width $=12.7 \mathrm{~mm}$ ).

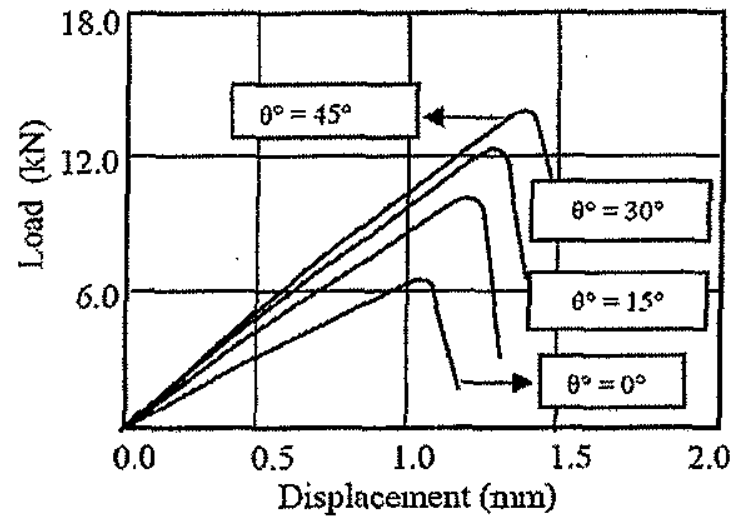

Fig. 12 Load-displacement diagram of cross-ply short beam shear specimens with different off axis angles (width $=25 \mathrm{~mm}$ ).

Fig. 14 shows a comparison between the values of interlaminar shear strength obtained by SBS (width=12.7 mm) and DNS (shear length= $0 \mathrm{~mm}$ ) tests. The results in this figure have a reasonable agreement between the values of ILSS in DNS and SBS tests. The lower values of SBS specimens may be due to the resin microcracks or the bending stress (interlaminar shear failure must occurs at mid-plane of test specimen. Sometimes it occurs close to midplane but in this case, a bending stress component appears so the interlaminar shear stress component decreases).



Fig. 13 Relationship between the off-axis angle and the interlaminar shear strength for both double-notch and short-beam shear tests.

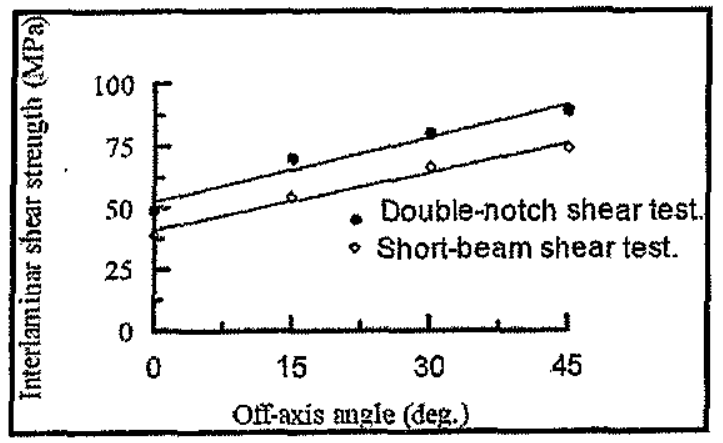

Fig. 14 Relationship between the off-axis angle and the interlaminar shear strength for both double-notch and short-beam shear tests.

\section{- Failure modes}

After testing, the failed specimens were examined. The detailed failure modes are described below, Fig. 15.

1) Specimens with $7.5 \mathrm{~mm}$ width have one horizontal crack quite close to the mid thickness, extending from the loading point to one end, and crossing the entire width. The crack could be seen by looking at the side of the specimen as shown in Fig. 15(a). Most of the specimens also had a slight indentation at the touch points of the loading noses. These specimens appear to have failure in pure shear.

2) Specimens with $12.7 \mathrm{~mm}$ width have one horizontal crack quite close to the mid thickness, extending from the loading point to one end, and crossing the entire width. The crack could be seen by looking at the side of the specimen. Most of the specimens also had a slight indentation at the 
touch points of the loading noses. These specimens appear to have failure in pure shear.

3) All $25 \mathrm{~mm}$ wide specimens have horizontal splits accompanied with vertical crack. Broken fibers and resin cracks can be seen on the specimen tensile side (which does not fail in interlaminar mode Fig, 15(b)).


(b)

Fig. 15 (a) Specimens fail in interlaminar mode.

(b) Specimens do not fail in interlaminar mode.

Figs. 16 to 18 show the failure modes of short-beam cross-ply specimens with off-axis angles $\left(\theta=0^{\circ}, 15^{\circ}\right.$, $30^{\circ}$, and $45^{\circ}$ ) and with widths (w- 7.5, 12.7, and 25 $\mathrm{mm})$.

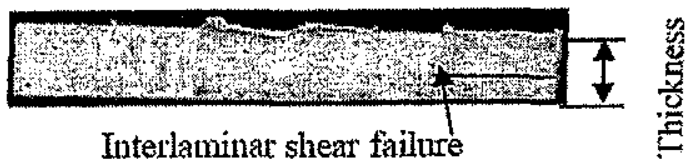

(a)



Interlaminar shear failure

(b)



Interlaminar shear failure Damage on the tensile side

(c)

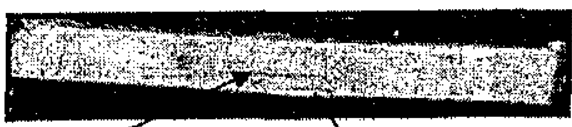

Interlaminar slyear failure Damage on the tensile side

(d)

Fig.16 Failure modes of SBS cross-ply GFRP specimens with (a) $0^{\circ}$, (b) $15^{\circ}$, (c) $30^{\circ}$, (d) $45^{\circ}$ off-axis angles (width $=7.5 \mathrm{~mm}$ ).

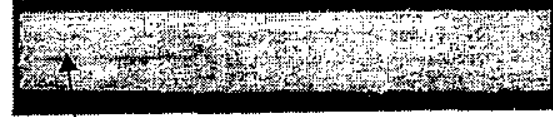

Tnterlaminar shear failure

(a)

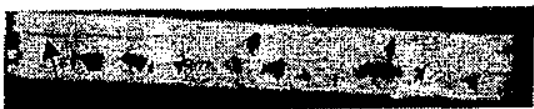

Interlaminar shear failure

(b)

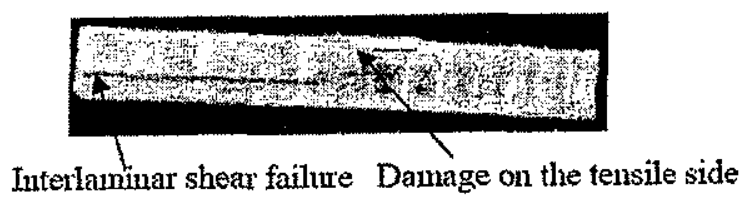

(c)

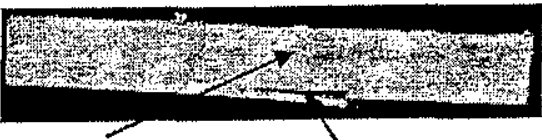

Interlaminar shear failure Damage on the tensile side

(d)

Fig. 17 Failure modes of SBS cross-ply GFRP specimens with (a) $0^{\circ}$, (b) $15^{\circ}$, (c) $30^{\circ}$, (d) $45^{\circ}$ offaxis angles (width $=12.7 \mathrm{~mm}$ ).

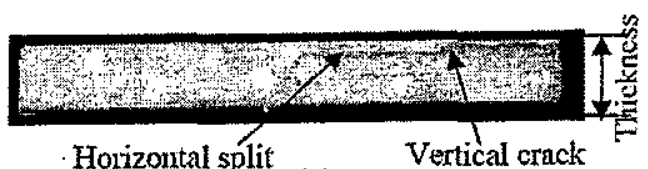

(a)

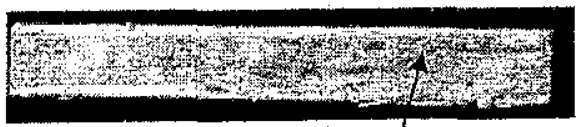

Separation between layers

(b)

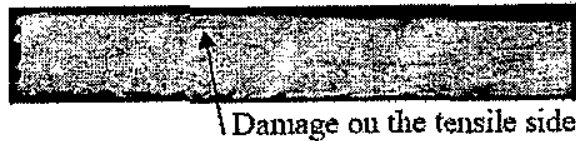

(c)

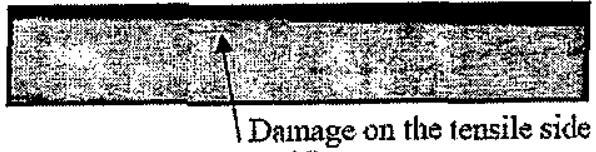

(d)

Fig. 18 Failure modes of SBS cross-ply GFRP specimens with (a) $0^{\circ}$, (b) $15^{\circ}$, (c) $30^{\circ}$, (d) $45^{\circ}$ offaxis angles (width $=25 \mathrm{~mm}$ ).

From these figures it can be seen that, in all cases damage on the tensile side is observed in addition to the horizontal crack. The damage could have occurred after the drop in load prior to interlaminar shear failure. After the damage, the capability of resisting shear for the specimen will not be as good as it was previously. Therefore, the existence of 
damage can be expected to reduce the apparent interlaminar shear strength.

\section{THEORETICAL WORK}

\subsection{Prediction of Interlaminar Shear Stress in DNS Specimens}

One of the key limitations of the Classical Lamination Theory is that each ply is assumed to be in-plane stress in the xy plane, and that interlaminar stresses associated with $\mathrm{z}$ axis are neglected. Such interlaminar stresses can cause delamination, or separation of the laminae.

A state of plane stress actually does exist in the laminae of a laminate in regions sufficiently far away from geometric discontinuities such as free edges. A three-dimensional elasticity solution by Pipes and Pagano [14] has shown that even in a laminate under simple uniaxial loading, there is a boundry layer region along the free edges where a threedimensional state of stress exists.

The behavior of interlaminar shear stress near the free edge in a laminate will be demonstrated by using the following equation from the theory of elasticity:

$\frac{\partial \sigma_{x}}{\partial x}+\frac{\partial \tau_{x y}}{\partial y}+\frac{\partial \tau_{x z}}{\partial z}=0.0$

For the uniaxially loaded laminate, the stresses do not vary along the loading direction (the $\mathrm{x}$ axis). It follows that $\frac{\partial \sigma_{x}}{\partial x}=0.0$ and from Eq. (3), the interlaminar shear stress, $\tau \times z(z)$, is given by :

$\tau_{x z}(z)=-\int_{-\frac{t}{2}}^{z} \frac{\partial \tau_{x y}}{\partial y} d z$

The in-plane shear stress, $\tau_{x y}$, has a constant value given by CLT in the interior region of the laminae. In the boundry layer, $\tau_{x y}$ decreases from its constant value to zero value at the stress-free surfaces.

In the region $0 \leq y \leq(b-a)$ [15].

$\tau_{x y}=\tau_{c}$ (in-plane shear stress)

$\tau_{x z}(z)=-\int_{-\frac{t}{2}}^{z} \frac{\partial \tau_{x y}}{\partial y} d z=0$

where: $2 b$ is the specimen width.

$a$ is the boundry layer width

$\tau_{\mathrm{c}}$ is assumed to be the shear stress from the Classical Lamination Theory.

In the boundry layer region $(b-a) \leq y \leq b$

$\tau_{\mathrm{xy}}=\frac{\tau_{c}}{a^{2}}(\mathrm{y}-\mathrm{b})(\mathrm{b}-2 \mathrm{a}-\mathrm{y}$ $\tau_{x z}(z)=-\int_{-\frac{t}{2}}^{z} \frac{\partial \tau_{x y}}{\partial y} d z=\frac{2 \tau_{x y}}{a^{2}}(y-(b-a)) \times(z+(t / 2))$

From Eq. 5,6 $\tau_{x y}, \tau_{x z}$ were calculated and the interlaminar shear stress distribution were drawn for cross-ply specimens with different $\theta^{\circ}$, Fig. 19. Interlaminar shear stress distribution was drawn for $z$ $=0$ (a distance from the neutral axis) where fracture occured.

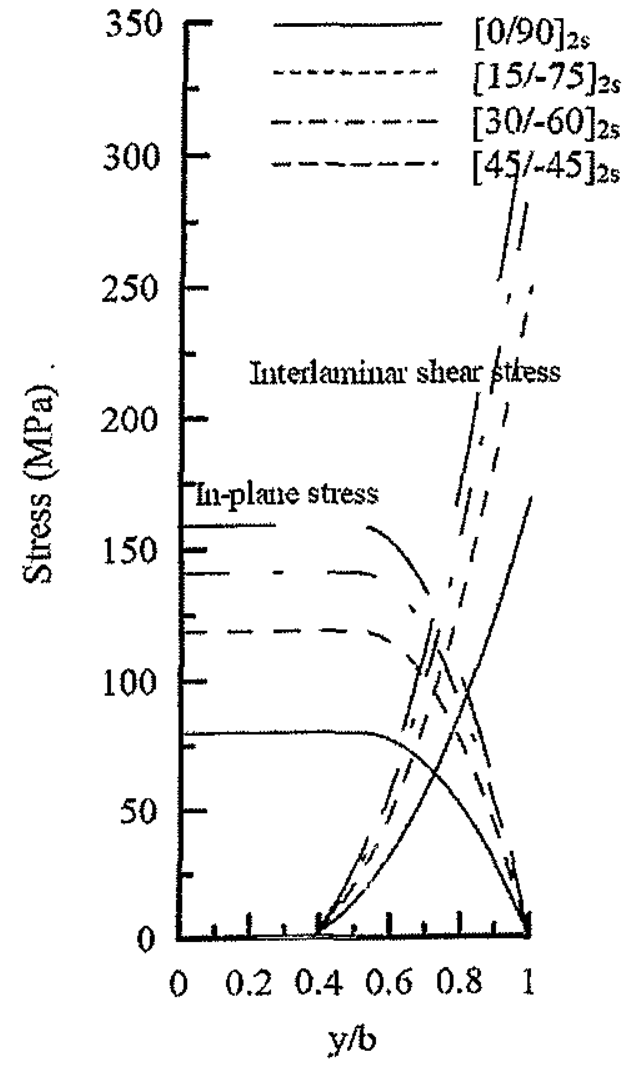

Fig. 19 Schematic representation of in-plane and interlaminar shear stress distributions of $\left[0^{\circ} / 90^{\circ}\right] 2 \mathrm{~s}$, [15/-75]2s, [30/-60]2s, [45/-45]2s DNS specimens.

\subsection{Prediction of Interlaminar Shear Stress in SBS Specimens}

The interlaminar shear stress at the $\mathrm{k}^{\text {th }}$ ply $\left(\tau_{x z}\right)_{k}$ in short-beam shear specimen is given [15] by:

$\left(\tau_{x z}\right)_{k}=\frac{3 V}{2(2 b) t}\left[\frac{S}{E_{F L}}\right]$

where; $\mathrm{S}=\frac{4}{N^{2}} \sum_{j=k}^{N / 2}\left(E_{x}\right)_{j}(2 j-1)$

The effective flexural modulus (EFL) can be calculated from equation (9)

$E_{F L}=\frac{8}{N^{3}} \sum_{j=1}^{N / 2}\left(E_{x}\right)_{j}\left(3 j^{2}-3 j+1\right)$ 
The modulus of elasticity at different angles $\left(E_{\theta}\right)$ is calculated from the following equation:

$$
E_{x(\theta)}=\frac{1}{\frac{1}{E_{11}} c^{4}+\left[\frac{-2 v_{12}}{E_{11}}+\frac{1}{G_{12}}\right] c^{2} s^{2}+\frac{1}{E_{22}} s^{4}}
$$

where; $c=\cos \theta, \mathrm{s}=\sin \theta$.

$N:$ The total number of plies.

$2 \mathrm{~b}:$ The specimen width $(\mathrm{mm})$.

$t:$ The specimen thickness (mm).

$V:$ The transverse shear force $(N)$.

The interlaminar shear stress at the kth ply for a beam with an even number of uniform thickness plies is given by Eq. (7). For a given cross-section and a given stacking sequence, the ratio $\frac{3 V}{2(2 b) t}$ can be set to a constant, $\mathrm{K}$ and the shear stress can be written as $\left(\tau_{x z}\right)_{k}=K\left[\frac{S}{E_{F L}}\right]$, where $\mathrm{S}$ and $E_{F L}$ are defined by Eqs. (8), (9). The shear stress distribution can then be determined to within a constant $\mathrm{K}$ by finding the variation of $\left[\frac{S}{E_{F L}}\right]$ across the thickness as shown in Figs.20-23.

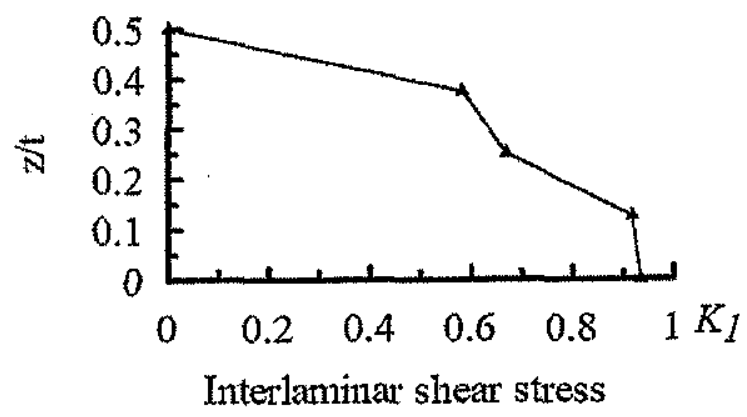

Fig.20 Interlaminar shear stress distribution in crossply SBS specimen.

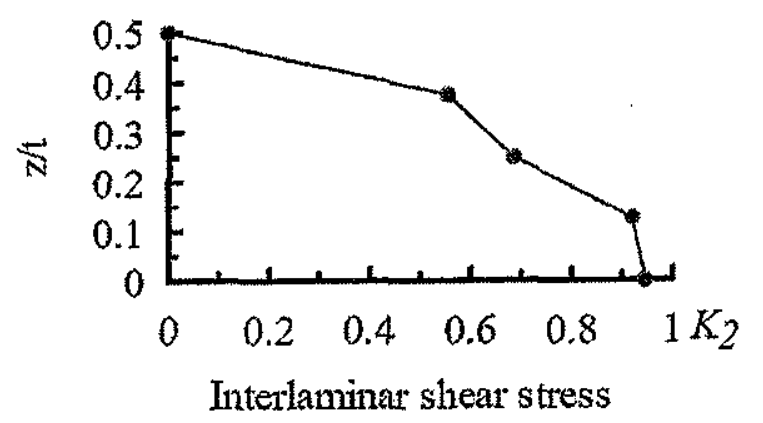

Fig. 21 Interlaminar shear stress distribution in [15\% $\left.75^{\circ}\right]_{2 s}$ SBS specimen.

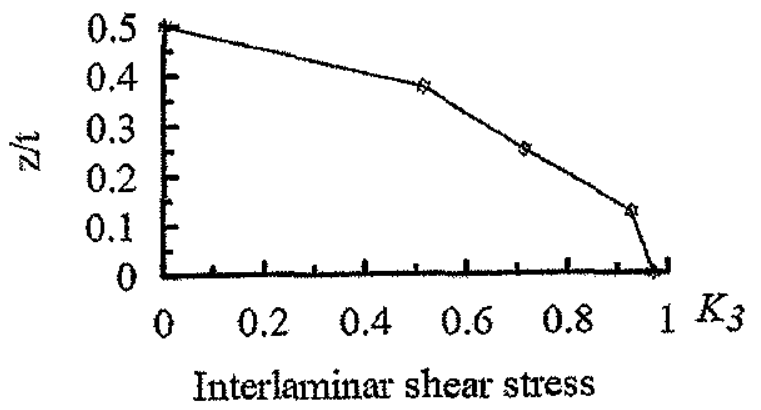

Fig. 22 Interlaminar shear stress distribution in [30\% $\left.60^{\circ}\right]_{25}$ SBS specimen.

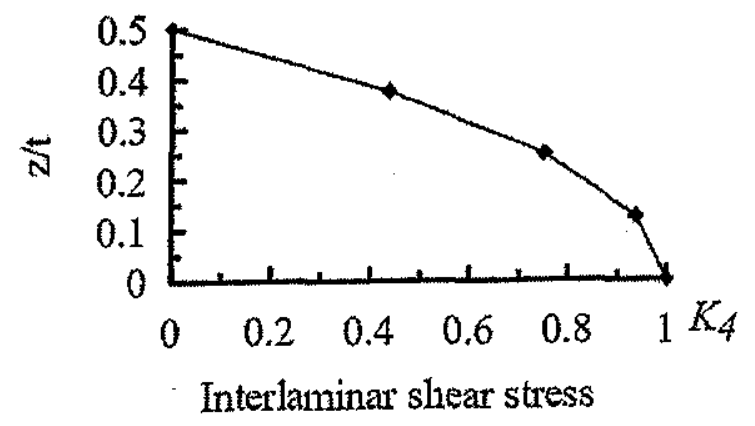

Fig. 23 Interlaminar shear stress distribution in [45\% $\left.45^{\circ}\right]_{2 \mathrm{~s}}$ SBS specimen.

\section{CONCLUSIONS}

1-The main characteristic of double-notch shear curve is that these curves have a linear behavior up to the maximum point followed by a catastrophic failure, while the main characteristic of the shortbeam shear curve is that, These curves have approximately linear relationship up to the maximum point. Close to the breaking point, the load deflection curves exhibit load drops, indicating that damage is developing in the specimens.

2- In double-notch shear test, Interlaminar shear strength decreases with the increasing of the shear length. In short-beam shear test, The interlaminar shear stress shows a slight increasing trend as the width is reduced.

3- The maximum interlaminar shear strength is found for specimens with $45^{\circ}$ off-axis angle, [45\% $\left.45^{\circ}\right] 2$ s. On the other hand specimens with $0^{\circ}$ offaxis angle have the minimum interlaminar shear strength.

4- In double-notch shear test, The failure of $\left[0^{\circ} / 90^{\circ}\right] 2 \mathrm{~s}$ specimens started by visible cracks across the width of the specimen (across the shear plane between the two centrally located notches) perpendicular to the loading direction (in $90^{\circ}$ direction) followed by visible and complete separation between the two central layers. In crossply with $15^{\circ}, 30^{\circ}, 45^{\circ}$ off-axis angles, fracture 
features are nearly the same as the previous case. The only difference is that cracks were initiated at $-75^{\circ},-60^{\circ},-45^{\circ}$ central plies.

5- In SBS test, failed specimens showed a complex failure mechanism. The optimum specimen width is necessary in order to induce interlaminar shear failures. For $\mathrm{w}=7.5,12.7 \mathrm{~mm}$ specimens, the bending stress is not high enough to damage the specimens before interlaminar shear failure. Therefore, the short-beam shear test for these specimens is valid for measuring the interlaminar shear strength. The maximum shear stress at the mid-plane of the specimen between the loading and support cylinders was used to correlate with the apparent interlaminar shear strength. The shortbeam shear test method must be used with caution when measuring the interlaminar shear strength.

6- Interlaminar shear strengths determined using double-notch shear test agree very well with those determined by short-beam shear test.

\section{REFERENCES}

[1] Shindo $Y$, Wang R, and Horiguchi $K$, "Analytical and Experimental Studies of Short-Beam Interlaminar Shear Strength of G-10CR GlassCloth/Epoxy Laminates at Cryogenic Temperatures" ASME, Vol. 123, pp. 112-118, (2001).

[2] Kasen MB, "Current Status of Interlaminar Shear Testing of Composite Material at Cryogenic Temperatures", Adv. Cryog. Eng., Vol. 36, pp. 787-792, (1990).

[3] Evans D, Johnson I, Jones H, and Hughes DD, "Shear Testing of Composite Structures at Low Temperatures", Adv. Cryog. Eng., Vol. 36, pp. 819-826, (1990).

[4] Becker $\mathrm{H}$, "Problems of Cryogenic Interlaminar Shear Strength Testing", Adv. Cryog. Eng., Vol. 36 , pp. 827-834, (1990).

[5] Unal O, Narottam P, and Bansal, "In-plane and Interlaminar Shear Strength of a Unidirectional
Hi-Nicalon Fiber-Reinforced Celsian Matrix Composite", Ceramics International, Vol.28, pp. 527-540, (2002).

[6] Khashaba UA, "Shear Behavior of Unidirectional GFRP Composite",6th Int. Conference on Prod. Eng. Design \& Control, Alexandria, Egypt, 1517 February (1997).

[7] Shindo $Y$, Wang $R$, Horiguchi $K$, and Ueda $S$,"Theoretical and Experimental Evaluation of Double-Notch Shear Strength of G-10CR GlassCloth/Epoxy Laminates at Cryogenic Temperatures", ASME J. Eng. Mater. Techno., Vol. 121, No. 3, pp. 367-373, (1999).

[8] ASTM, "Standard Test Method for Shear Properties of Composite Materials by the Vnotched Beam Method", Designation D5379-93, (1993).

[9] Han L, "The Shear Properties of Angle Ply Laminates", MS.C. Thesis, Chemical Engineering Dep., Toronto University, (1998).

[10] ASTM, "Standard Test Method for In- Plane Shear Strength of Reinforced Plastics", Designation D2346-02, (2002).

[11] ASTM, "Standard Test Method for Apparent Interlaminar Shear Strength of Parallel Fiber Composites by Short-Beam Method", Designation D2344-84, (1984).

[12] BS 3691, "E-glass Fiber Roving for Reinforcement of Polyester and Epoxy Resin Systern", (1990).

[13] Shaw RM, and Sims GD, "Round-robin Validation Exercise for The Determination of Through-thickness Shear Strength in Compression", March (2003).

[14] Pipes RB, and Pagano NJ, "Interlaminar Stresses in Composite Laminates Under Uniform Axial Extension", Journal of of Composite Materials, Vol. 4, pp. 538-548, (1970).

[15] Gibson RF, "Principles of Composite Material Mechanics", McGraw-Hill, Inc.; (1994). 